\title{
A Pilot Study on Hip Bone Mineral Densities Estimation from Forearm CBCT images
}

\author{
Hoon Ko ${ }^{1,2,9}$, Chang-Hoon Lee ${ }^{2,3, \uparrow}$, Kwanmoon Jeong ${ }^{1,2}$, Myeung Su Lee ${ }^{2,3}$, Yunyoung Nam, \\ Kwon-Ha Yoon ${ }^{2,5}$ and Jinseok Lee ${ }^{1,2}$ \\ ${ }^{1}$ Department of Biomedical Engineering, Wonkwang University College of Medicine, \\ 460 Iksandeaero, Iksan, Jeonbuk 570-749, Korea \\ [e-mail: \{idayfly8710, kor.kwanmoon, gonasago\}@gmail.com] \\ ${ }^{2}$ Imaging Science based Lung and Bone Disease Research Center, Wonkwang University, \\ 460 Iksandeaero, Iksan, Jeonbuk 570-749, Korea \\ [e-mail: \{lch110, ckhlms, khy1646\}@wku.ac.kr] \\ ${ }^{3}$ Department of Rheumatology Internal Medicine, Wonkwang University College of Medicine, \\ 460 Iksandeaero, Iksan, Jeonbuk 570-749, Korea \\ ${ }^{4}$ Department of Computer Science, Soonchunhyang University, Asan, Chungnam, 336-745, Korea \\ [e-mail: ynam@sch.ac.kr] \\ ${ }^{5}$ Department of Radiology, Wonkwang University College of Medicine, \\ 460 Iksandeaero, Iksan, Jeonbuk 570-749, Korea \\ *Corresponding author: Jinseok Lee \\ "These authors contributed equally to this work.
}

Received June 9, 2017; revised July 31, 2017; accepted August 14, 2017;

published December 31, 2017

\begin{abstract}
In this paper, we defined the relative cross-sectional area of forearm cortical bone and investigated its correlation with hip bone mineral density values of total femur, femoral neck, femoral trochanter, femoral inter-trochanter and femoral ward's triangle, respectively. Based on the correlations, we established a linear transformation between the relative cross-sectional area of forearm cortical bone and each hip bone BMD. We obtained forearm images using CBCT and hip bone BMDs using dual-energy X-ray absorptiometry (DXA) for 28 subjects. We also investigated the optimal forearm region to provide the strongest correlation coefficient. We used the optimized forearm region to establish each linear transformation to estimate BMD values for total femur, femoral neck, femoral trochanter, femoral inter-trochanter and femoral ward's triangle from the relative cross-sectional area of forearm cortical bone, respectively. We observed the strong correlations with total femur ( $\mathrm{r}=0.889)$, femoral neck ( $\mathrm{r}=0.924)$, femoral trochanter $(\mathrm{r}=0.821)$, femoral inter-trochanter $(\mathrm{r}=0.867)$ and femoral ward's triangle $(r=0.895)$, respectively. The strongest correlation was observed in the forearm mid-shaft regions. Our results suggest that the hip bone BMD values can be simply estimated from forearm CBCT images in a convenient sitting position without $\mathrm{X}$-ray exposure on a hip including genital organs, and may be useful for screening osteoporosis.
\end{abstract}

Keywords: Cone beam computed tomography (CBCT), cortical bone, forearm, pelvic bones, bone mineral density (BMD)

This work was funded by Wonkwang University in 2015. 


\section{Introduction}

$\mathbf{O}_{\text {steoporosis is characterized by low bone strength with micro-architectural deterioration of }}$ the bone tissue [1-5]. Bone material and structural properties determine bone strength, which is assessed by a bone densitometry for further information of fracture risk, diagnosing osteoporosis, and bone mineral density (BMD) monitoring. To quantify BMD value, dual-energy X-ray absorptiometry (DXA) and quantitative computed tomographic imaging (QCT) are widely used in clinical practice. DXA uses x-ray beam with two different average $\mathrm{X}$-ray energies and measures the attenuation at high and low energies for the area density calculation [6-9]. DXA measures at axial sites such as spine and hip. QCT uses a standard X-ray CT scanner with a calibration standard to convert Hounsfield Units (HU) of the CT image to BMD values [10-13]. Similarly, QCT primarily evaluates BMD at lumbar spine and hip. Even though the two methods are optimized tools, especially for the assessment of hip BMD, they can be applied only in the supine position [12, 14-16]. The scanning of the hip in a supine position affects the genital organs. Because X-ray exposure is one of the main risk factors for cancer occurrence, scanning of the hip region that includes the genital organs may lead to apprehension in the scanned patients. Furthermore, it is difficult to diagnose osteoporosis based on hip bone BMD in patients who have undergone hip replacement. We recently found a strong correlation between relative cross-sectional area of forearm cortical bone and femoral neck BMD [17]. This correlation reflects that the quality and loading properties of the femur and radius are related because they are both appendicular bones, and the relative cross-sectional area of forearm cortical bone can predict the BMD value of the femoral neck: the BMD of the femoral neck can be estimated by scanning a forearm using peripheral cone beam computed tomography (CBCT) in a convenient sitting position without $\mathrm{X}$-ray exposure to the hip region that includes the genital organs.

In this paper, we further investigated and extended the correlations between five hip bone BMD values and the relative cross-sectional areas of forearm cortical bone: total femur, femoral trochanter, femoral inter-trochanter, and femoral ward's triangle as well as femoral neck. We first defined the relative cross-sectional area of forearm cortical bone, and found its strong correlation with the total femur $(r=0.889)$, femoral neck $(r=0.924)$, femoral trochanter $(r=0.821)$, femoral inter-trochanter $(r=0.867)$, and femoral ward's triangle $(r=$ 0.895). In addition, we established each linear transformation to estimate BMD values of the total femur, femoral neck, femoral trochanter, femoral inter-trochanter, and femoral ward's triangle from the relative cross-sectional area of forearm cortical bone. Our findings indicate that hip bone BMD can be estimated using forearm images from a peripheral CBCT.

\section{Materials and Methods}

\subsection{Subjects and Measurements}

The Wonkwang university hospital (WKUH) Institutional Review Board (IRB) approved the image measurement and analysis protocol. Subjects were provided written consent to participate in the study. We obtained forearm images of 28 subjects using peripheral CBCT (PHION, Nano Focus Ray, Jeonju, Korea). The study subjects consisted of 8 men and 20 women with a mean age of 57.86 years. Among them, 14 osteoporosis patients and 14 non-osteoporosis subjects were involved in this pilot study. Their detailed demographic data are summarized in Table 1. 
Table 1. Demographic data of the subjects

\begin{tabular}{|c|c|c|c|}
\hline Subject & $\begin{array}{c}\text { Non-Osteoporosis } \\
(n=14)\end{array}$ & $\begin{array}{c}\text { Osteoporosis } \\
(\mathrm{n}=14)\end{array}$ & $\begin{array}{l}\text { All Subjects } \\
(\mathrm{n}=28)\end{array}$ \\
\hline \multirow{2}{*}{ Sex (n) } & Male 7 & Male 1 & Male 8 \\
\hline & Female 7 & Female 13 & Female 20 \\
\hline Age (years) & $50.57 \pm 19.35$ & $69.7 \pm 6.62$ & $57.86 \pm 10.40$ \\
\hline 20-30(n) & 5 & 0 & 5 \\
\hline $50-59(n)$ & 3 & 1 & 4 \\
\hline 60-69 (n) & 5 & 5 & 10 \\
\hline $70-79(n)$ & 1 & 8 & 9 \\
\hline Height $(\mathrm{cm})$ & $165.14 \pm 10.44$ & $151.9 \pm 8.34$ & $158.54 \pm 11.46$ \\
\hline Weight (kg) & $64.43 \pm 7.37$ & $51.2 \pm 8.80$ & $57.86 \pm 10.40$ \\
\hline BMI $\left(\mathrm{kg} / \mathrm{m}^{2}\right)$ & $23.70 \pm 2.70$ & $22.1 \pm 2.19$ & $22.89 \pm 2.55$ \\
\hline $\mathrm{BMD}^{\mathrm{TF}}\left(\mathrm{g} / \mathrm{cm}^{2}\right)$ & $0.94 \pm 0.09$ & $0.69 \pm 0.08$ & $0.82 \pm 0.14$ \\
\hline $\mathrm{BMD}^{\mathrm{FN}}\left(\mathrm{g} / \mathrm{cm}^{2}\right)$ & $0.76 \pm 0.12$ & $0.54 \pm 0.07$ & $0.65 \pm 0.14$ \\
\hline $\operatorname{BMD}^{\mathrm{FT}}\left(\mathrm{g} / \mathrm{cm}^{2}\right)$ & $0.85 \pm 0.22$ & $0.53 \pm 0.07$ & $0.69 \pm 0.23$ \\
\hline $\operatorname{BMD}^{\mathrm{FI}}\left(\mathrm{g} / \mathrm{cm}^{2}\right)$ & $1.09 \pm 0.11$ & $0.84 \pm 0.10$ & $0.96 \pm 0.16$ \\
\hline $\mathrm{BMD}^{\mathrm{WT}}\left(\mathrm{g} / \mathrm{cm}^{2}\right)$ & $0.59 \pm 0.18$ & $0.32 \pm 0.11$ & $0.45 \pm 0.20$ \\
\hline
\end{tabular}

$\mathrm{BMD}^{\mathrm{TF}}$ : total femur BMD obtained from DXA, BMD ${ }^{\mathrm{FN}}$ : femoral neck BMD obtained from DXA. BMD ${ }^{\mathrm{FT}}$ : femoral trochanter obtained from DXA. BMD ${ }^{\mathrm{FI}}$ : femoral inter-trochanter obtained from BMD. BMD ${ }^{\mathrm{WT}}$ : femoral ward's triangle obtained from DXA. Values are means \pm SD

\subsection{Relative Cross-Sectional Area of Forearm Cortical Bone}

With the peripheral CBCT, we set the scanning parameters: a tube voltage of $130 \mathrm{kvp}$, a tube current of $8 \mathrm{~mA}$, scanning times of 7.5 seconds, and image matrixes of 1024 x 1024 pixels with a thickness of $0.2162 \mathrm{~mm}$. The scanning regions were obtained roughly from the carpal bone to the elbow, which included the forearm mid-shaft. The total slice image number was 797. We defined the relative cross-sectional area of forearm cortical bone (RAFC) by the following formula:

$$
R A F C=\frac{\left(A r_{c}^{r}+A r_{c}^{u}\right)}{\left(A r_{T}^{r}+A r_{T}^{u}\right)}=\frac{\left(A r_{T}^{r}+A r_{T}^{u}\right)-\left(A r_{t}^{r}+A r_{t}^{u}\right)}{\left(A r_{T}^{r}+A r_{T}^{u}\right)}
$$

where $A r_{c}^{r}$ and $A r_{c}^{u}$ are the cross-sectional areas of radius and ulna, respectively, in a forearm cortical bone; $A r_{t}^{r}$ and $A r_{t}^{u}$ are the areas in a trabecular bone, and $A r_{T}^{r}$ and $A r_{T}^{u}$ are the areas in a total bone including a cortical and a trabecular bones. That is, RAFC is the ratio of forearm cortical bone to the cross-sectional area. We obtained the forearm images from CBCT and quantified RAFC from cross-sectional images to investigate the correlations with hip bone BMDs: total femur, femoral neck, femoral trochanter, femoral inter-trochanter and femoral ward's triangle, which BMD values were measured by DXA (Discovery-W scanner, Hologic Inc., Bedford, MA). The entire measurement and analysis procedure were confirmed by three radiologists in Wonkwang University Hospital (WKUH).

\subsection{Computation of RAFC from Peripheral CBCT images}

To obtain the cross-sectional cortical bone region, a periosteal contour was first segmented by delineating mineralized bone and extra-osseal soft tissue. Subsequently, an endosteal contour was segmented by delineating the endocortical boundary from the cancelleous compartment 
$[18,19]$. The periosteal surface was extracted by a threshold technique followed by filling-up inside as shown in Fig. 1 (a) to (c). The periosteal surface area from a radius and an ulna are expressed by $A r_{T}^{r}$ and $A r_{T}^{u}$, respectively. The endosteal surface was extracted by masking the periosteal surface in Fig. 1 (c) with the bone mask from the original image in Fig. 1 (a).

Based on the black and white image in Fig. 1 (c), the periosteal contour was peeled to leave only the marrow pixels, and then filling-up inside was applied as shown in in Fig. 1 (d) to (g) [20]. Finally, the endosteal surface from periosteal surface was subtracted to obtain the mineralized cortical bone region as shown in Fig. 1 (j), which is the difference image between the image $A$ and $B$. in Fig. 1 (h) and (i). The areas of cortical radius $A r_{c}^{r}$ and ulna $A r_{c}^{u}$ were calculated by counting the number of pixels inside the extracted cortical bone region.

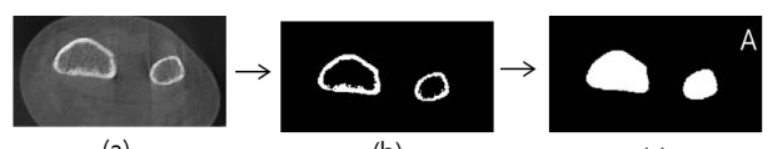

(a)

(b)

(c)

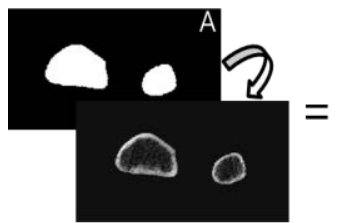

(d)

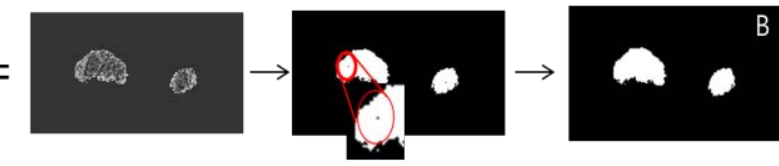

(e)

(f)

(g)

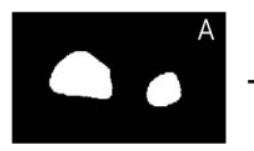

(h)

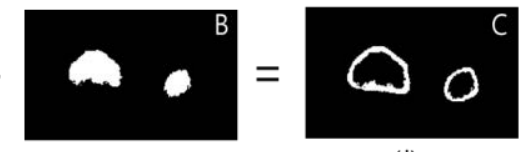

(i) (j)

Fig. 1. Segmentation of cortical bone and total bone

The areas of cortical radius $A r_{c}^{r}$ and ulna $A r_{c}^{u}$ were repeatedly computed for all the 797 slice images, which were scanned through a forearm. For the experiment, we used the 797 slice images, which were commonly scanned for all subjects. As post-processing, three radiologists found a 50-slice mid-shaft area that was defined as region $M$. Thus, we divided the forearm image with 50-slice images. The next adjacent 50-slice image region in the proximal direction was defined as region $P 1$. In the distal direction, the next adjacent 50-slice image region was defined as region $\mathrm{D} 1$, and other 50 -slice image regions in the distal direction were defined as regions $D 2$ to $D 8$ as shown in Fig. 2. In this way, we grouped the ten 50-slice image regions, and $R A F C^{G}$ were defined as the mean value of RAFC in the region $G$, where $G \in\{D 1$, D2, D3, D4, D5, D6, D7, D8, M, P1\}. 


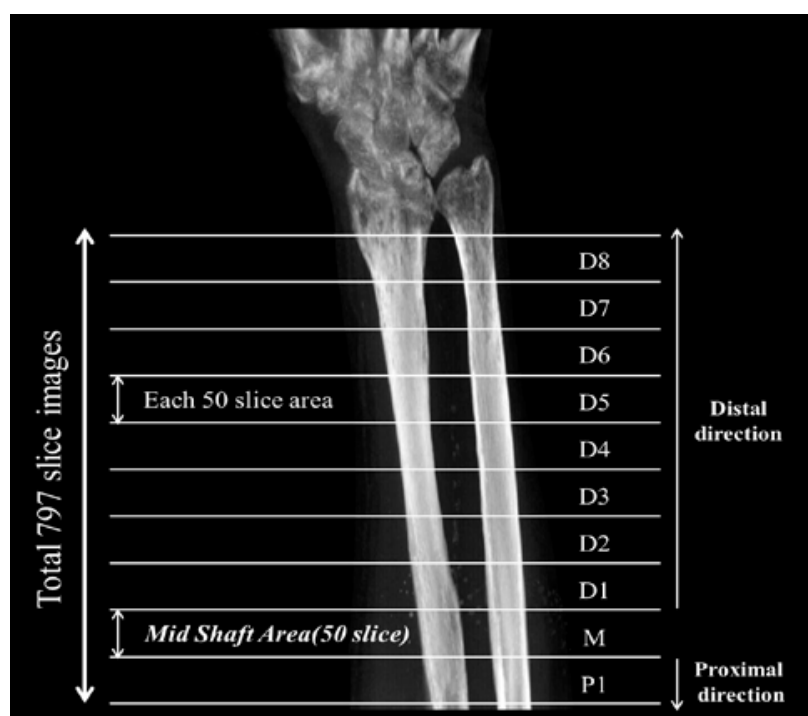

Fig. 2. The obtained slice images were grouped into 10 regional areas, each with 50 slice images

\subsection{Regression of $\mathrm{BMD}^{f}$ from RAFC ${ }^{\mathrm{G}}$}

We investigated the correlation of $\mathrm{RAFC}^{\mathrm{G}}$ and hip bone BMDs from total femur, femoral neck, femoral trochanter, femoral inter-trochanter and femoral ward's triangle. We assumed that $\mathrm{RAFC}^{\mathrm{G}}$ and hip bone BMD values were related by a linear transformation as per the following formula:

$$
\begin{aligned}
B M D^{T F} & \approx \widetilde{B M D}^{T F(G)}=k^{T F(G)} \cdot R A F C^{G}+c^{T F(G)} \\
B M D^{F N} & \approx \widetilde{B M D}^{F N(G)}=k^{F N(G)} \cdot R A F C^{G}+c^{F N(G)} \\
B M D^{F T} \approx \widetilde{B M D}^{F T(G)}=k^{F T(G)} \cdot R A F C^{G}+c^{F T(G)} & \\
B M D^{F I} & \approx \widetilde{B M D}^{F I(G)}=k^{F I(G)} \cdot R A F C^{G}+c^{F I(G)} \\
B M D^{W T} & \approx \widetilde{B M D}^{W T(G)}=k^{W T(G)} \cdot R A F C^{G}+c^{W T(G)}
\end{aligned}
$$

where $\overparen{B M D}$ represents the estimated BMD value, $\mathrm{k}$ and $\mathrm{c}$ are the scaling and offset constants, respectively: TF, FN, FT, FI and WT represent total femur, femoral neck, femoral trochanter, femoral inter-trochanter and femoral ward's triangle, respectively.

\subsection{Statistical Analyses}

Statistical analyses were performed using IBM SPSS Statistics for Windows, version 22.0 (IBM Corp.). The Pearson's correlation coefficients were used for calculating linear regression analysis. The correlation between $\mathrm{RAFC}^{\mathrm{G}}$ and each BMD was analyzed using correlation coefficient $r$. The linear regression lines with $k$ and $c$ were determined using the least-squares method. Root mean square error (RMSE) and mean absolute percentage error (MAPE) were calculated in order to evaluate this estimation as defined by the following formula: 


$$
\begin{gathered}
R M S E=\sqrt{\frac{1}{n} \sum_{i=1}^{n}(B M D-\overparen{B M D})^{2}} \\
M A P E=\frac{1}{n} \sum_{i=1}^{n}\left|\frac{(B M D-\overparen{B M D})}{B M D}\right| \times 100
\end{gathered}
$$

where RMSE values were calculated based on BMD and $\overparen{\mathrm{BMD}}$ according to each slice image region G and each different hip bone: TF, FN, FT, FI and WT. Given the established linear regression, the statistical t-test for regression slope was performed. The test determines whether there is a significant linear relationship between the independent variable RAFC ${ }^{G}$ and the dependent variable each BMD. To apply the linear regression t-test, we calculated standard error of the slope and found the p-value. The p-value tests the null hypothesis that the slope is zero (no effect). A low p-value $(<0.05)$ indicates that one can reject the null hypothesis.

\section{Result}

\subsection{Correlation between Hip Bone BMD values and RAFC ${ }^{G}$}

Fig. 3 shows the correlation coefficient values between each BMD and RAFC ${ }^{G}$, where $\mathrm{G} \ni$ \{D1, D2, D3, D4, D5, D6, D7, D8, M, P1\}, for TF, FN, FT, FI, and WT. The correlation coefficient $r$ was highest in the $\mathrm{M}$ and $\mathrm{D} 1$ regions for all hip bones of TF, FN, FT, FI, and WT. The correlation coefficients tended to decrease in the regions further away from the region $\mathrm{M}$ in both directions. Table 2 summarizes the correlation coefficient $r$ values of the hip bone $B M D$ values regarding $\mathrm{RAFC}^{\mathrm{G}}$ in the regions $\mathrm{M}$ and D1. Especially in the region $\mathrm{M}$ corresponding to a mid-shaft, the correlation values were $0.889,0.924,0.821,0.867$, and 0.895 for TF, FN, FT, FI, and WT, respectively.

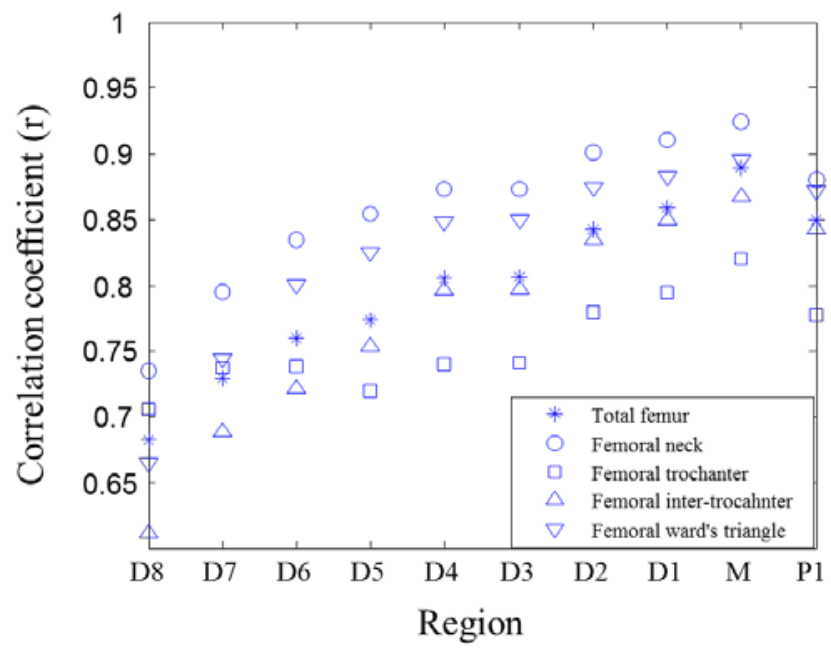

Fig. 3. Correlation coefficent values between each BMD value and RAFC ${ }^{\mathrm{G}}$, for TF,FN,FT,FI and WT. 
Table 2. Mean correlation coefficeint $r$ values according to $\mathrm{RAFC}^{\mathrm{G}}$ and position

\begin{tabular}{|c|c|c|}
\hline Correlation Coefficients & Region $\boldsymbol{M}$ & Region D1 \\
\hline \hline$B M D^{T F}$ vs $R A F C^{G}$ & 0.889 & 0.859 \\
\hline$B M D^{F N}$ vs $R A F C^{G}$ & 0.924 & 0.911 \\
\hline$B M D^{F T}$ vs $R A F C^{G}$ & 0.821 & 0.795 \\
\hline$B M D^{F I}$ vs $R A F C^{G}$ & 0.867 & 0.85 \\
\hline$B M D^{W T}$ vs $R A F C^{G}$ & 0.985 & 0.883 \\
\hline
\end{tabular}

\subsection{BMD Estimation $\overline{\text { BMD }}$ from RAFC ${ }^{G}$}

Based on the observed high correlation coefficient $r$ values in the region $M$, we plotted the regression plots for TF, FN, FT, FI and WT, respectively, as shown in Fig. 4 to 8.

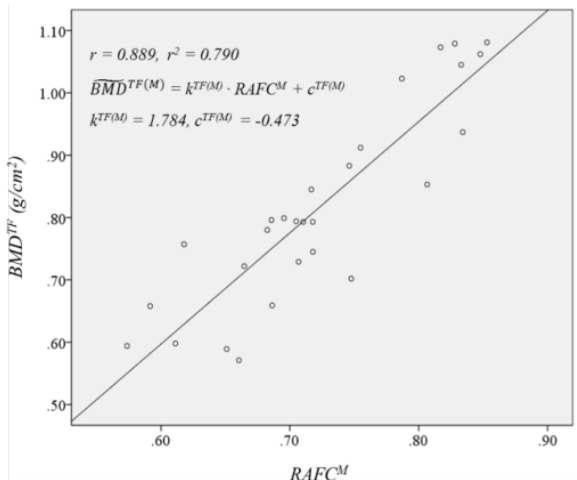

(a)

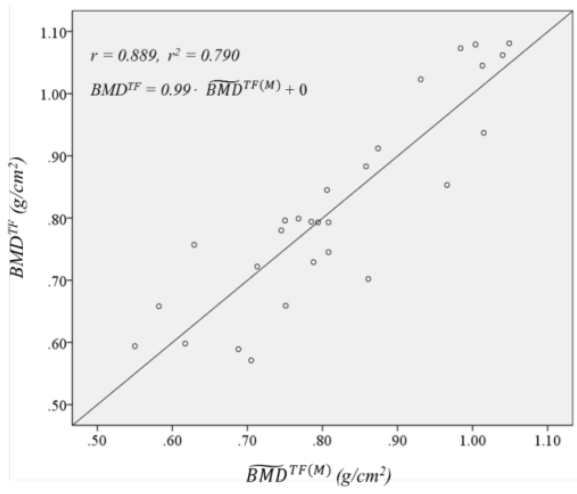

(b)

Fig. 4. Correlation of total femur; (a) Regression plot of $\mathrm{RAFC}^{\mathrm{M}}$ versus $\mathrm{BMD}^{\mathrm{TF}}$.

(b) Correlation plot of $\widehat{\mathrm{BMD}}^{\mathrm{TF}(\mathrm{M})}$ versus $\mathrm{BMD}^{\mathrm{TF}}$.

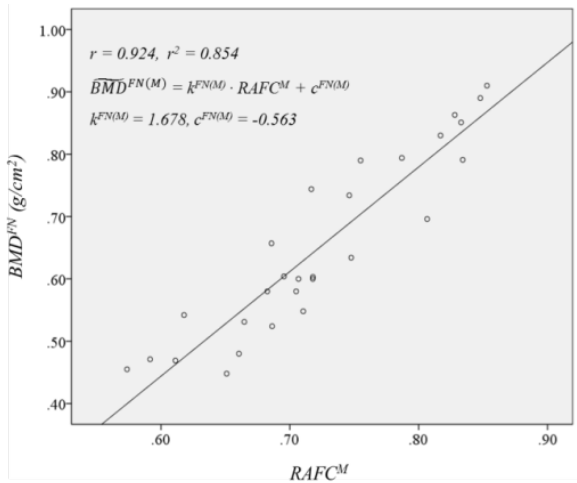

(a)

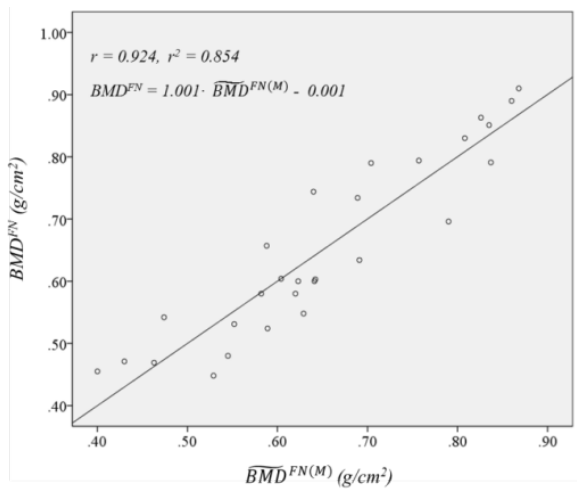

(b)

Fig. 5. Correlation of femoral neck; (a) Regression plot of $\mathrm{RAFC}^{\mathrm{M}}$ versus $\mathrm{BMD}^{\mathrm{FN}}$. (b) Correlation plot of $\widetilde{\mathrm{BMD}}^{\mathrm{FN}(\mathrm{M})}$ versus $\mathrm{BMD}^{\mathrm{FN}}$. 


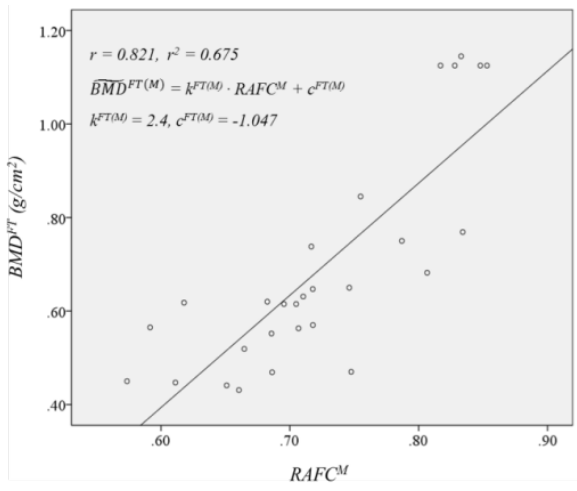

(a)

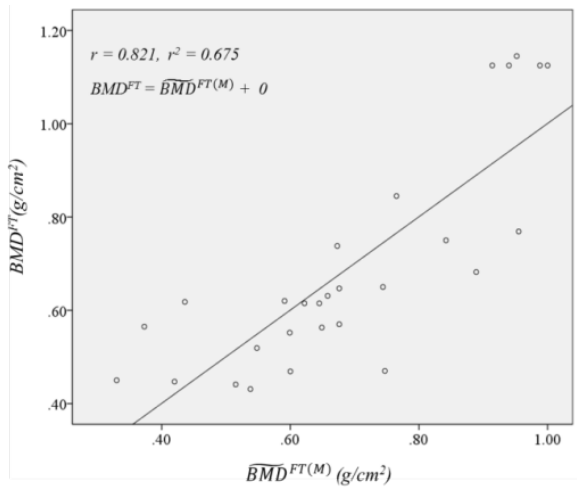

(b)

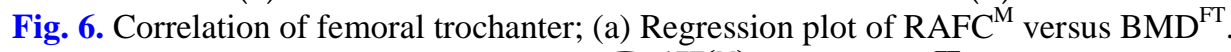
(b) Correlation plot of $\widetilde{\mathrm{BMD}}^{\mathrm{FT}(\mathrm{M})}$ versus $\mathrm{BMD}^{\mathrm{FT}}$.

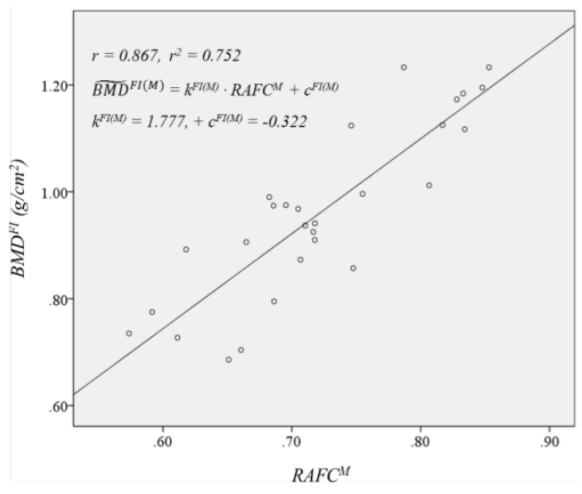

(a)

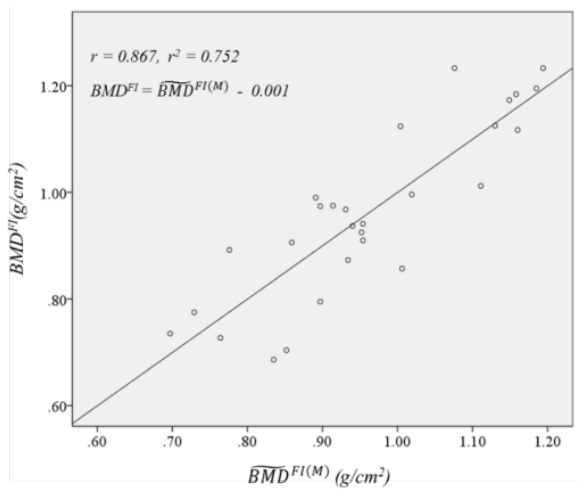

(b)

Fig. 7. Correlation of femoral inter-trochanter; (a) Regression plot of RAFC ${ }^{\mathrm{M}}$ versus $\mathrm{BMD}^{\mathrm{FI}}$. (b) Correlation plot of $\widehat{\mathrm{BMD}}^{\mathrm{FI}(\mathrm{M})}$ versus $\mathrm{BMD}^{\mathrm{FI}}$.

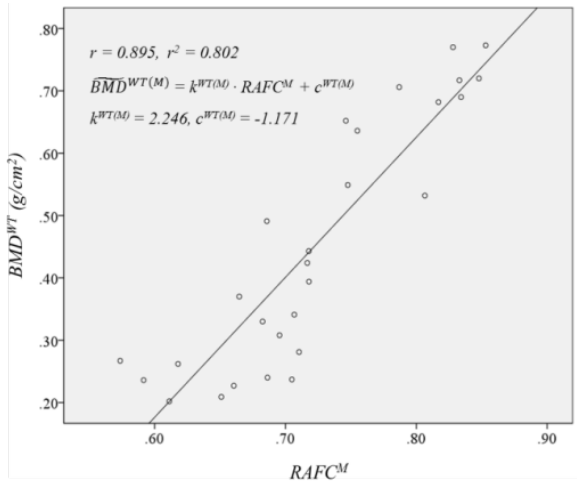

(a)

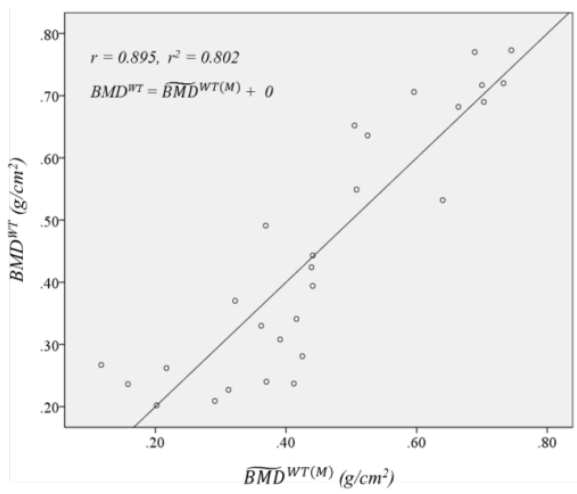

(b)

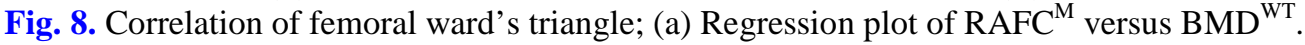
(b) Correlation plot of $\widehat{B M D}^{\mathrm{WT}(\mathrm{M})}$ versus $\mathrm{BMD}^{\mathrm{WT}}$. 
We further investigated the linear transformation of the form in Equations (9) to (13) for TF, FN, FT, FI and WT, respectively. For TF, we found the values of $k^{T F(G)}$ and $c^{T F(G)}$ with 1.784 and -0.473 , respectively. In addition, for FN, FT, FI and WT, we found the values $k^{F N(G)}$ with 1.678, $c^{F N(G)}$ with $-0.563, k^{F T(G)}$ with $2.400, c^{F T(G)}$ with $-1.047, k^{F I(G)}$ with 1.777, $c^{F I(G)}$ with $-0.322, k^{W T(G)}$ with 2.246, and $c^{W T(G)}$ with -1.171. In summary, the experimental relationship between $R A F C^{M}$ and each $B M D$ was as follows:

$$
\begin{aligned}
& B M D^{T F} \approx \overparen{B M D}^{T F(G)}=1.784 \cdot R A F C^{M}-0.473 \\
& B M D^{F N} \approx \overparen{B M D}^{F N(G)}=1.678 \cdot R A F C^{M}-0.563 \\
& B M D^{F T} \approx \overparen{B M D}^{F T(G)}=2.400 \cdot R A F C^{M}-1.047 \\
& B M D^{F I} \approx \widetilde{B M D}^{F I(G)}=1.777 \cdot R A F C^{M}-0.322 \\
& B M D^{W T} \approx \widetilde{B M D}^{W T(G)}=2.246 \cdot R A F C^{M}-1.171
\end{aligned}
$$

The statistical $t$-tests for regression slopes for all TF, FN, FT, FI and WT revealed significant linear relationships between each $R A F C^{M}$ and each BMD value. We further used the estimated BMD $\overparen{B M D}$ to calculate the RMSEs and MAPEs from each BMD value. Table 3 summarizes the RMSEs and MAPEs between each $\overparen{B M D}$ and each BMD value. For TF, RMSE and MAPE were $0.0720 \mathrm{~g} / \mathrm{cm}^{2}$ and $7.74 \%$. For FN, RMSE and MAPE were 0.0543 $\mathrm{g} / \mathrm{cm}^{2}$ and $7.63 \%$. For FT, RMSE and MAPE were $0.1305 \mathrm{~g} / \mathrm{cm}^{2}$ and $16.68 \%$. For FI, RMSE and MAPE were $0.0799 \mathrm{~g} / \mathrm{cm}^{2}$ and $7.14 \%$. For WT, RMSE and MAPE were $0.0874 \mathrm{~g} / \mathrm{cm}^{2}$ and $20.77 \%$.

Table 3. Root mean square errors (RMSEs) and mean absolute percentage errors (MAPEs) between $\widehat{\mathrm{BMD}}$ and BMD

\begin{tabular}{|c|c|c|}
\hline \multirow{2}{*}{ Errors } & $\begin{array}{c}\text { RMSE } \\
\text { (Root Mean Square Error) }\end{array}$ & $\begin{array}{c}\text { MAPE } \\
\text { (Mean Absolute Percentage Error) }\end{array}$ \\
\hline \hline$\widetilde{\mathrm{BMD}}^{\mathrm{TF}(\mathrm{M})}$ & $0.0720 \mathrm{~g} / \mathrm{cm}^{2}$ & $7.74 \%$ \\
\hline$\widetilde{\mathrm{BMD}}^{\mathrm{FN}(\mathrm{M})}$ & $0.0543 \mathrm{~g} / \mathrm{cm}^{2}$ & $7.63 \%$ \\
\hline$\widetilde{\mathrm{BMD}}^{\mathrm{FT}(\mathrm{M})}$ & $0.1305 \mathrm{~g} / \mathrm{cm}^{2}$ & $16.68 \%$ \\
\hline$\widetilde{\mathrm{BMD}}^{\mathrm{FI}(\mathrm{M})}$ & $0.0799 \mathrm{~g} / \mathrm{cm}^{2}$ & $7.14 \%$ \\
\hline$\widetilde{\mathrm{BMD}}^{\mathrm{WT}(\mathrm{M})}$ & $0.0874 \mathrm{~g} / \mathrm{cm}^{2}$ & $20.77 \%$ \\
\hline
\end{tabular}

Fig. 9. shows the Bland-Altman plots for TF, FN, FT, FI and WT. We found a systematic bias of $-0.0011 \mathrm{~g} / \mathrm{cm}^{2}$ with a standard deviation of $0.0733 \mathrm{~g} / \mathrm{cm}^{2}$ for TF. Additionally, a systematic bias of $-0.0007 \mathrm{~g} / \mathrm{cm}^{2}$ with a standard deviation of $0.0551 \mathrm{~g} / \mathrm{cm}^{2}$ for FN, a systematic bias of $0.0014 \mathrm{~g} / \mathrm{cm}^{2}$ with a standard deviation of $0.1329 \mathrm{~g} / \mathrm{cm}^{2}$ for FT, a systematic bias of $0.0007 \mathrm{~g} / \mathrm{cm}^{2}$ with a standard deviation of $0.0814 \mathrm{~g} / \mathrm{cm}^{2}$ for FI, and a systematic bias of $-0.0007 \mathrm{~g} / \mathrm{cm}^{2}$ with a standard deviation of $0.0886 \mathrm{~g} / \mathrm{cm}^{2}$ for WT. These results show that there are a strong correlations between hip bone BMDs and $R A F C^{M}$ and it is possible to predict the hip bone BMDs from forearm images. 


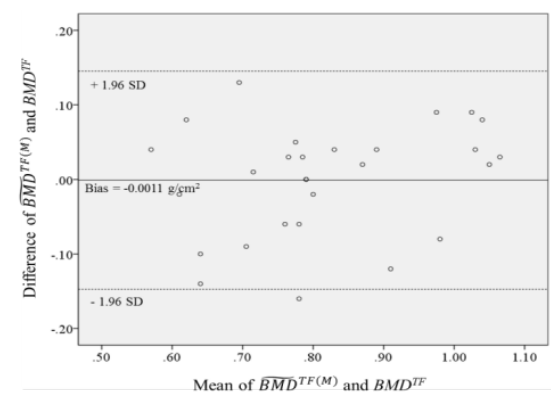

(a)

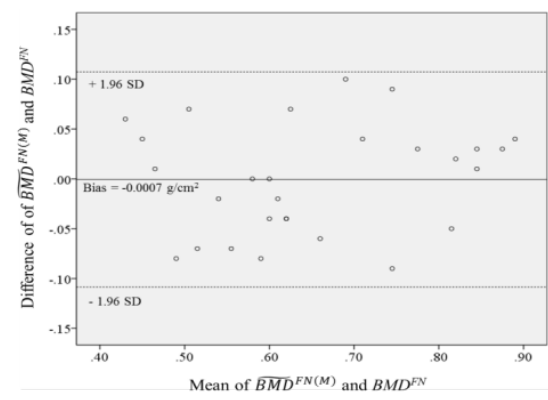

(b)

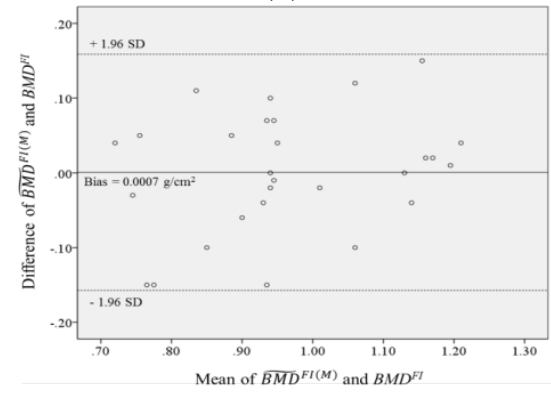

(d)

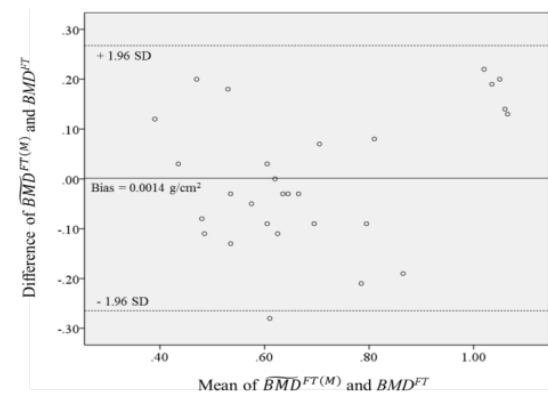

(c)

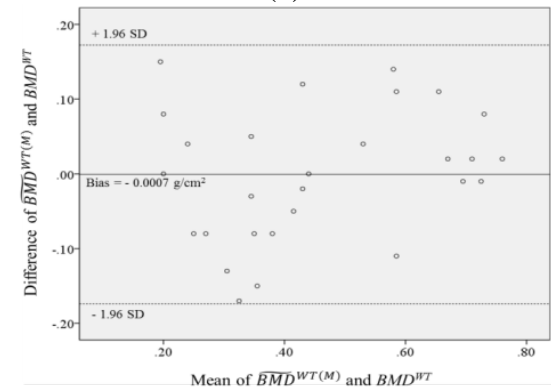

(e)

Fig. 9. Bland-Altman plots: (a) total femur, (b) femoral neck, (c) femoral trochanter, (d) femoral inter-trochanter and (e) femoral ward's triangle

\section{Discussion}

Bone strength changes with age because a remodeling process with several factors of thickness, size, density and architecture in cortical and trabecular bones. In our study, we intended to identify that the cortical bone in a forearm and hip bones are correlated changed with age [21, 22]. In [23], a feasibility study was conducted that forearm BMD using DXA may predict hip osteoporosis. In [17, 24-26], the investigators showed that some parameters from the cortical bone in distal radius and ulna on anteroposterior radiograph could reflect the femoral neck BMD. In [24], the distal radius BMD was correlated with the ratio of the outside cortical shell diameter to the inside cortical shell diameter at the metaphyseal/diaphyseal junction. In [25], radiologic density of dental structure from CBCT imaging could provide information of lumbar vertebra and femoral neck. In [26], bicortical thickness of the distal radius was positively correlated with femoral neck BMD. Recently, it was reported that a femoral neck BMD is associated with the relative cortical bone area of forearm [17]. All these 
studies reflect that the bones in forearm and hip are correlated. Nevertheless, a study on the correlation of each part of the hip bones with forearm images has not been conducted.

In our study, we investigated the correlation between RAFC and five hip bone BMD values of total femur, femoral neck, femoral trochanter, femoral inter-trochanter and femoral ward's triangle. We also investigated the entire range of a forearm, and found that the best position providing the highest correlation value was a mid-shaft region. To further analysis, we investigated the correlation values of other three additional parameters: cross-sectional areas of a cortical bone, a trabecular bone and a total bone in a mid-shaft. Table 4 summarizes the comparison of the correlation coefficient values with cross-sectional areas of a cortical bone, a trabecular bone area and a total bone in a mid-shaft as well as $R A F C^{M}$. It shows that the correlation coefficients from the absolute values of cross-sectional areas are lower than $R A F C^{M}$.

Table 4. Comparison with cross-sectional areas of a cortical bone, a trabecular bone area and a total bone in a mid-shaft.

\begin{tabular}{|c|c|c|c|c|}
\hline Correlation r & $\boldsymbol{R A F C}^{\boldsymbol{M}}$ & $\begin{array}{c}\text { Cortical bone of } \\
\text { region M }\end{array}$ & $\begin{array}{c}\text { Trabecular bone } \\
\text { of region M }\end{array}$ & $\begin{array}{c}\text { Total bone of } \\
\text { region M }\end{array}$ \\
\hline \hline$B M D^{T F}$ & 0.889 & 0.694 & -0.258 & 0.513 \\
\hline$B M D^{F N}$ & 0.924 & 0.581 & -0.437 & 0.351 \\
\hline$B M D^{F T}$ & 0.821 & 0.666 & -0.127 & 0.535 \\
\hline$B M D^{F T}$ & 0.867 & 0.620 & -0.309 & 0.430 \\
\hline$B M D^{W T}$ & 0.895 & 0.388 & -0.668 & 0.101 \\
\hline
\end{tabular}

Our proposed method is easily reproducible because of the simple steps using CBCT. The CBCT technique is currently used for clinical diagnosis, especially for peripheral use [27-30]. It provides two-dimensional and three-dimensional images for the radiographed area with a relatively low cost as compared to conventional CT. The radiation dose is comparable to that of panoramic imaging in the case of small field of views. Due to the low cost and low radiation dose, it became popular, its use widespread. In this pilot study, we obtain the forearm bone CT images using CBCT, especially for mid-shaft area. Subsequently, the $R A F C^{M}$ is measured automatically based on the cortices thickness to the amount of total bone. Lastly, each hip bone BMD of FN, FT, FI and WT is estimated using the established equation between each hip bone BMD and the measured $R A F C^{M}$. In addition, one of the advantages in our method is that only a forearm, especially the mid-shaft area, needs to be exposed via X-ray while DXA and QCT requires the scanning of entire axial skeleton near hip bones. Because the cancer occurrence by X-ray exposure is one of the main factors, the X-ray exposure of the only forearm mid-shaft area is better than that of the axial skeleton near hip area. To further validate these clinical results, future studies with a larger subject population are needed.

\section{Conclusion}

We defined the relative cross-sectional area of forearm cortical bone and observed the strong correlations with total femur ( $r=0.889)$, femoral neck $(r=0.924)$, femoral trochanter $(r=0.821)$, femoral inter-trochanter $(r=0.867)$ and femoral ward's triangle $(r=0.895)$, respectively. Our results suggest that DXA-based hip bone BMD values can be accurately estimated using forearm CBCT images and may be used in an osteoporosis screening system, with patients placed in a convenient sitting position. Peripheral CBCT-based BMD measurement may provide significant value for prevention and early treatment and management of osteoporosis. 


\section{References}

[1] J. A. Kanis, "Diagnosis of osteoporosis and assessment of fracture risk," The Lancet, vol. 359, ed, pp. 1929-1936, 2002. Article (CrossRef Link)

[2] S. Schuit, M. Van der Klift, A. Weel, C. De Laet, H. Burger, E. Seeman, A. Hofman, A. Uitterlinden, J. Van Leeuwen and H. Pols, "Fracture incidence and association with bone mineral density in elderly men and women: the Rotterdam Study," Bone, vol. 34, ed, pp. 195-202, 2004.

Article (CrossRef Link)

[3] G. Guglielmi, S. Muscarella and A. Bazzocchi, "Integrated imaging approach to osteoporosis: state-of-the-art review and update," Radiographics, vol. 31, ed, pp. 1343-1364, 2011. Article (CrossRef Link)

[4] J. Aitken, "Relevance of osteoporosis in women with fracture of the femoral neck," Br Med J (Clin Res Ed), vol. 288, ed, pp. 597-601, 1984. Article (CrossRef Link)

[5] C. Christodoulou and C. Cooper, "What is osteoporosis?," Postgraduate medical journal, vol. 79, ed, pp. 133-138, 2003. Article (CrossRef Link)

[6] J. Y. Yang and Y. M. Kim, "Correlation analysis of BMD in proximal femur and spine," Journal of the Korean Society of Fractures, vol. 16, ed, pp. 570-576, 2003. Article (CrossRef Link)

[7] G. M. Blake and I. Fogelman, "Bone densitometry and the diagnosis of osteoporosis," Seminars in nuclear medicine, vol. 31, ed: Elsevier, pp. 69-81, 2001. Article (CrossRef Link)

[8] J. Jang, S. Yang, D. Kim, Y. Jo, S. Lee and K. Kim, "Comparative Study of Femur BMD and Lumbar BMD Measurement Using Dual Energy X-ray Absorptiometry in Proximal Femur Fractures," Korean journal of bone metabolism, vol. 3, ed, pp. 170-173, 1996.

[9] S. H. Ralston, "Bone densitometry and bone biopsy," Best Practice \& Research Clinical Rheumatology, vol. 19, ed, pp. 487-501, 2005. Article (CrossRef Link)

[10] K. Engelke, C. Libanati, Y. Liu, H. Wang, M. Austin, T. Fuerst, B. Stampa, W. Timm and H. K. Genant, "Quantitative computed tomography (QCT) of the forearm using general purpose spiral whole-body CT scanners: accuracy, precision and comparison with dual-energy X-ray absorptiometry (DXA)," Bone, vol. 45, ed, pp. 110-118, 2009. Article (CrossRef Link)

[11] D. M. Black, M. L. Bouxsein, L. M. Marshall, S. R. Cummings, T. F. Lang, J. A. Cauley, K. E. Ensrud, C. M. Nielson and E. S. Orwoll, "Proximal femoral structure and the prediction of hip fracture in men: a large prospective study using QCT," Journal of Bone and Mineral Research, vol. 23, ed, pp. 1326-1333, 2008. Article (CrossRef Link)

[12] T. Lang, G. Guglielmi, C. Van Kuijk, A. De Serio, M. Cammisa and H. Genant, "Measurement of bone mineral density at the spine and proximal femur by volumetric quantitative computed tomography and dual-energy X-ray absorptiometry in elderly women with and without vertebral fractures," Bone, vol. 30, ed, pp. 247-250, 2002. Article (CrossRef Link)

[13] G. Guglielmi, P. Schneider, T. Lang, G. Giannatempo, M. Cammisa and H. Genant, "Quantitative computed tomography at the axial and peripheral skeleton," European radiology, vol. 7, ed, p. S32, 1997. Article (CrossRef Link)

[14] N. Mochizuki, N. Sugino, T. Ninomiya, N. Yoshinari, N. Udagawa and A. Taguchi, "Association of cortical shape of the mandible on panoramic radiographs with mandibular trabecular bone structure in Japanese adults: a cone-beam CT-image analysis," Oral Radiology, vol. 30, ed, pp. 160-167, 2014. Article (CrossRef Link)

[15] K. Engelke, J. E. Adams, G. Armbrecht, P. Augat, C. E. Bogado, M. L. Bouxsein, D. Felsenberg, M. Ito, S. Prevrhal and D. B. Hans, "Clinical use of quantitative computed tomography and peripheral quantitative computed tomography in the management of osteoporosis in adults: the 2007 ISCD Official Positions," Journal of Clinical Densitometry, vol. 11, ed, pp. 123-162, 2008. Article (CrossRef Link)

[16] A. Vijay, N. Shankar, C. A. S. Ligesh and M. Anburajan, "Evaluation of osteoporosis using CT image of proximal femur compared with dual energy X-ray absorptiometry (DXA) as the standard," in Proc. of Electronics Computer Technology (ICECT), 2011 3rd International Conference on, vol. 3, ed: IEEE, pp. 334-338, 2011. Article (CrossRef Link) 
[17] K. Jeong, H. Ko, C.-H. Lee, M. S. Lee, K.-H. Yoon and J. Lee, "A novel method for estimation of femoral neck bone mineral density using forearm images from peripheral cone beam computed tomography," Applied Sciences, vol. 6, ed, p. 113, 2016. Article (CrossRef Link)

[18] W.-Y. Ma and B. S. Manjunath, "EdgeFlow: a technique for boundary detection and image segmentation," IEEE transactions on image processing, vol. 9, ed, pp. 1375-1388, 2000. Article (CrossRef Link)

[19] S. Shah, A. Abaza, A. Ross and H. Ammar, "Automatic tooth segmentation using active contour without edges," in Proc. of Biometric consortium conference, 2006 biometrics symposium: Special session on research at the, ed: IEEE, pp. 1-6, 2006. Article (CrossRef Link)

[20] S. C. DeFreitas, "Computer method for filling a selected region in a target image," ed: Google Patents, 1999.

[21] L. Mosekilde, "Age-related changes in bone mass, structure, and strength-effects of loading," Zeitschrift für Rheumatologie, vol. 59, ed, pp. I1-I9, 2000. Article (CrossRef Link)

[22] A.-M. Laval-Jeantet, C. Bergot, R. Carroll and F. Garcia-Schaefer, "Cortical bone senescence and mineral bone density of the humerus," Calcified tissue international, vol. 35, ed, pp. 268-272, 1983. Article (CrossRef Link)

[23] W. Trivitayaratana and P. Trivitayaratana, "The accuracy of bone mineral density at distal radius on non-forearm osteoporosis identification," Journal of the Medical Association of Thailand= Chotmaihet thangphaet, vol. 84, ed, pp. 566-571, 2001. Article (CrossRef Link)

[24] S. Rausch, K. Klos, F. Gras, H. K. Skulev, A. Popp, G. O. Hofmann and T. Mückley, "Utility of the cortical thickness of the distal radius as a predictor of distal-radius bone density," Archives of trauma research, vol. 2, ed, p. 11, 2013. Article (CrossRef Link)

[25] I. Barngkgei, I. Al Haffar and R. Khattab, "Osteoporosis prediction from the mandible using cone-beam computed tomography," Imaging science in dentistry vol. 44, ed, pp. 263-271, 2014. Article (CrossRef Link)

[26] T. Webber, S. P. Patel, M. Pensak, O. Fajolu, T. D. Rozental and J. M. Wolf, "Correlation between distal radial cortical thickness and bone mineral density," The Journal of hand surgery, vol. 40, ed, pp. 493-499, 2015. Article (CrossRef Link)

[27] B. Chen and R. Ning, "Cone - beam volume CT breast imaging: Feasibility study," Medical physics, vol. 29, ed, pp. 755-770, 2002. Article (CrossRef Link)

[28] W. C. Scarfe and A. G. Farman, "What is cone-beam CT and how does it work?," Dental Clinics of North America, vol. 52, ed, pp. 707-730, 2008. Article (CrossRef Link)

[29] J. Casselman, K. Gieraerts, D. Volders, J. Delanote, K. Mermuys, B. Foer and G. Swennen, "Cone beam CT: non-dental applications," Journal of the Belgian Society of Radiology, vol. 96, ed, 2013. Article (CrossRef Link)

[30] P. S. Cho, R. H. Johnson and T. W. Griffin, "Cone-beam CT for radiotherapy applications," Physics in medicine and biology, vol. 40, ed, p. 1863, 1995. Article (CrossRef Link) 

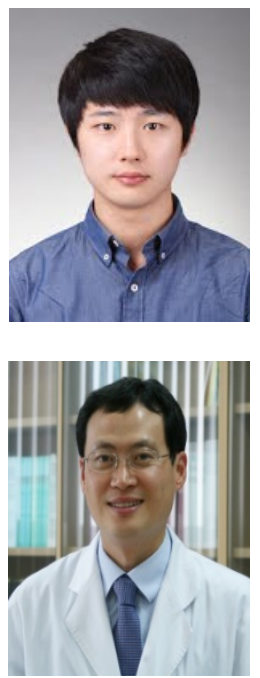

Chang-Hoon Lee received the Ph.D degree in medicine from posgraduate school, Chonbuk National University Medical School in 2015, and M.D. degree in medicine from chonnam University Medical School in 2001. He is currently an Associate Professor of Internal Medicine at Wonkwang University College of Medicine. His research interests are differentiation of osteoclast, osteoporosis treatment and biomedical signal processing.

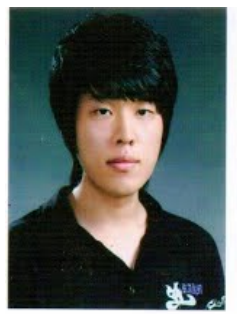

Kwanmoon Jeong received the B.S. in radiological science at Jeonju University and M.S. in biomedical engineering at Wonkwang University College of Medicine. His research interests include bio and image signal processing.
Ko received the B S. in radiological science at Jeonju University and interests include bio and image signal processing.$$
\text { His research interests include bio and image signal processing. }
$$
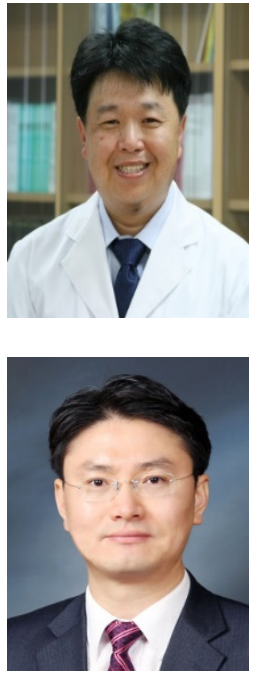


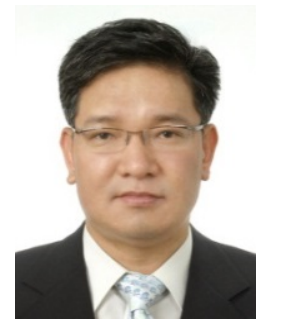

Kwon-Ha Yoon received his BS degree at college of medicine from Wonkwang University in 1992, and Ph.D. degrees at college of medicine from Jeonbuk National University in 2002 in South Korea. Currently, he is a professor at dept. of Radiology in college of medicine, WonKwang University. His main research interests include $\mathrm{x}$-ray imaging, nano medicine, molecular imaging, and gastointestinal imaging. He received awards for outstanding scientific paper published in Journal of Korean Radiological Society at April 1999 and Cum Laude from RSNA at December 2001. He is a member of KCR, RSNA, and ISMRM.

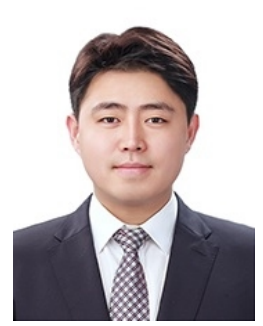

Jinseok Lee received Ph.D. degree in Electrical Engineering from Stony Brook University in 2009, and dual B.S. degrees in Electrical Engineering from Stony Brook University and Ajou University in 2005. He completed postdoctoral training in Biomedical Engineering, Worcester Polytechnic Institute in 2012. He is currently an Associate Professor of Biomedical Engineering at Wonkwang University College of Medicine. His research interests are medical instrumentation, wearable device, biosignal processing and robots. He is a Senior Member of IEEE. 